\title{
Desenvolvimento de amendoim consorciado com palma forrageira utilizando resíduo lácteo
}

\author{
Submetido - 31 jul. 2020 \\ Aprovado - 04 set. 2020 \\ Publicado - 14 out. 2020
}

http://dx.doi.org/10.17648/sas.v1i2.86

\begin{abstract}
Matheus de Almeida Lins (i)
Graduando em Agronomia - Universidade Federal do Agreste de Pernambuco, matheusalins@gmail.com. Jeandson Silva Viana $\mathbb{D}$ Doutor em Agronomia - Universidade Federal do Agreste de Pernambuco, jeandsonsv@yahoo.com.br.

Edilma Pereira Gonçalves (D) Doutora em Agronomia - Universidade Federal do Agreste de Pernambuco, edilmapg@hotmail.com. Graduando em Agronomia - Universidade Federal do Agreste de Pernambuco, joaopaulobiologia4@gmail.com.
\end{abstract}

\section{RESUMO}

Uma alternativa viável para o aproveitamento de pequenas áreas agrícolas é o cultivo em consórcio, aumentando a eficiência do uso da terra e reduzindo incidência de pragas e doenças. $O$ objetivo deste estudo foi avaliar os efeitos da população de plantas de amendoim (Arachis hypogaea L. cv. BR 1) consorciado com a palma forrageira (Opuntia ficus-indica L.) mais o emprego do rejeito lácteo sobre o desenvolvimento do amendoim. $O$ experimento foi conduzido em campo no município de Garanhuns, utilizou-se o delineamento de blocos ao acaso com 6 tratamentos, constituídos por diferentes populações de amendoim em monocultivo e consorciado com a palma forrageira. Avaliou-se massa seca e comprimento de parte aérea e raiz, área foliar, índice de velocidade de emergência e percentual de emergência. Foi empregado inoculante com estirpe de Bradyrhizobium comercial mais resíduo lácteo industrial em todos os tratamentos. $O$ consórcio propiciou aumento no comprimento de parte aérea e os melhores resultados foram observados no tratamento com duas linhas de amendoim em consórcio.

Palavras-chave: Arachis hypogaea L.; Consórcio; Opuntia ficus-indica.

\section{Growth of peanut plants intercropped with forage palm using dairy waste}

\section{ABSTRACT}

A viable way to utilize small agricultural areas is to intercrop agricultural crops, improving the earth efficient use and reducing the incidence of pests and diseases. The objective of this study was to evaluate the effects of the peanut (Arachis hypogaea L. CV. BR 1) plant population intercropped with forage palm (Opuntia ficus-indica L.) plus employee of industrial dairy waste on the peanut development. The experiment was conducted in field conditions at the municipality of Garanhuns in randomized block design with 6 treatments, composed by different peanuts plant population monocultivated and intercropped with forage palm. Were evaluated dry mass and length of aerial part and roots, leaf area, emergency speed index and emercency rate. Inoculant with commercial Bradyrhizobium strain plus industrial dairy waste in all treatments. The intercrop increased the length of aerial part and the best results were observed in the two peanuts lines intercropped with forage palm treatment. 


\title{
Desarrollo de maní intercalado con palma forrajera con residuos de leche
}

\begin{abstract}
RESUMEN
Una alternativa viable para el uso de pequeñas áreas agrícolas es el cultivo de consorcios, que aumenta la eficiencia del uso de la tierra y reduce la incidencia de plagas y enfermedades. El objetivo de este estudio fue evaluar los efectos de la población de plantas de maní (Arachis hypogaea L. cv. BR 1) intercaladas con palma forrajera (Opuntia ficus-indica L.) más el uso de desperdicios de leche en el desarrollo del maní. El experimento se realizó en el campo en el municipio de Garanhuns, utilizando un diseño de bloques al azar con 6 tratamientos, que consiste en diferentes poblaciones de maní en monocultivo e intercaladas con palma forrajera. Se evaluaron la masa seca y el brote y la longitud de la raíz, el área foliar, el índice de velocidad de emergencia y el porcentaje de emergencia. Estaba usando inoculante con la cepa comercial Bradyrhizobium más residuos lácteos industriales en todos los tratamientos. El consorcio proporcionó un aumento en la longitud del brote y los mejores resultados se observaron en el tratamiento con dos líneas de maní en el consorcio.
\end{abstract}

Palabras clave: Arachis hypogaea L.; Consorcios; Opuntia ficus-indica.

\section{Introdução}

O amendoim é uma das principais culturas cultivadas no semiárido nordestino para subsistência e se destaca como fonte de proteínas e carboidratos, além de apresentar facilidade de manejo e boa produtividade com uso mínimo de insumos agrícolas (LIMA, 2011).

Em pequenas propriedades, onde predomina o uso intensivo de mão de obra familiar, as culturas de subsistência são tradicionalmente produzidas em sistemas de consórcio (BEZERRA NETO et al., 1991). Esta prática reduz risco de perdas, a incidência de pragas, doenças e plantas daninhas durante 0 cultivo, melhora o uso eficiente da terra e agrega os benefícios econômicos da fixação de nitrogênio (ALTIEIRI et al., 2003; KASAl et al., 2011), de modo que pode-se utilizar a palma na alimentação animal e o amendoim na alimentação animal e humana, empregando os resíduos da cultura na alimentação animal, como sugerido por Ferreira et al. (2009). 
A palma forrageira é uma cultura bem adaptada às condições adversas do semiárido, desempenhando um papel muito importante nessas regiões na época de seca por suportar longos períodos de estiagem, alcançando produtividade de até 40 toneladas de matéria seca por hectare por colheita (SANTOS et al., 2006).

Além de ser amplamente produzido na região Agreste de Pernambuco devido à presença de indústrias de laticínios e um grande rebanho de bovinos leiteiros, o resíduo lácteo é rico em nutrientes, melhora as características físicas do solo, aumenta a retenção de água e incrementa a produtividade agrícola (MILKPOINT, 2009).

Esta pesquisa visou gerar informações sobre a utilização do resíduo industrial lácteo como fonte de nutrientes e o consórcio da palma forrageira com o amendoim para produtores da região, mediante possuir rebanho leiteiro de destaque produtivo na região do agreste pernambucano, assim contribuindo para sustentabilidade na agricultura, ampliação da renda do produtor e maximização da produtividade agropecuária da região.

O objetivo deste trabalho foi avaliar o efeito do monocultivo e do consórcio do amendoim cultivado em diferentes populações de plantas com a palma forrageira, e o efeito do resíduo lácteo sobre o crescimento e biomassa do amendoim.

\section{Material e métodos}

O experimento foi conduzido em condições de campo no município de Garanhuns. Em área pertencente à Universidade Federal Rural de Pernambuco (UFRPE), na Unidade Acadêmica de Garanhuns (UAG), localizada na Latitude $8^{\circ} 53^{\prime} 25^{\prime \prime}$ sul, longitude $36^{\circ} 29^{\prime} 34^{\prime \prime}$ oeste, a uma altitude média de $842 \mathrm{~m}$ do nível do mar.

O delineamento experimental utilizado foi de blocos ao acaso com parcelas subdivididas, onde foram testados sete tratamentos com quatro repetições, sendo T1 - Monocultivo com 1 linha de amendoim; T2 - Monocultivo 
de 2 linhas de amendoim; T3 - Monocultivo de 3 linhas de amendoim; T4 Palma forrageira consorciada com 1 linha de amendoim; T5 - Palma forrageira consorciada com 2 linhas de amendoim; T6 - Palma forrageira consorciada com 3 linhas de amendoim. Foi utilizada a cultivar de amendoim BR1 e a palma utilizada foi a espécie Opuntia ficus indica, conhecida popularmente como palma gigante ou redonda. A área experimental ocupada foi de $144 \mathrm{~m}^{2}$, dividida em blocos com $24 \mathrm{~m}^{2}$ e parcelas com $4 \mathrm{~m}^{2}$.

As mudas da palma foram plantadas no mês de junho de 2013, em espaçamento de $2,0 \mathrm{~m} \times 0,5 \mathrm{~m}$, e o semeio do amendoim foi realizado no mês de agosto de 2013 , com três densidades diferentes de plantio.

Os tratos culturais foram realizados conforme as exigências da cultura, consistindo em irrigação diária por microaspersão de modo a manter o solo com umidade, capinas semanais para eliminar plantas daninhas e observação de presença de pragas e doenças, que não causaram danos.

Foi realizada adubação com $60 \mathrm{~kg} / \mathrm{ha}$ de sulfato de potássio tendo como base o manual de recomendação de adubação para o Estado de Pernambuco, segunda aproximação (CAVALCANTI, 2008). Para fósforo não foi necessário realizar adubação, pois a análise de solo (Tabela 1) apresentou valor de Fósforo $(\mathrm{P})$ suficiente.

Tabela 1: Características químicas do solo utilizado para o plantio de amendoim em Garanhuns - PE (UFRPE/UAG, 2014).

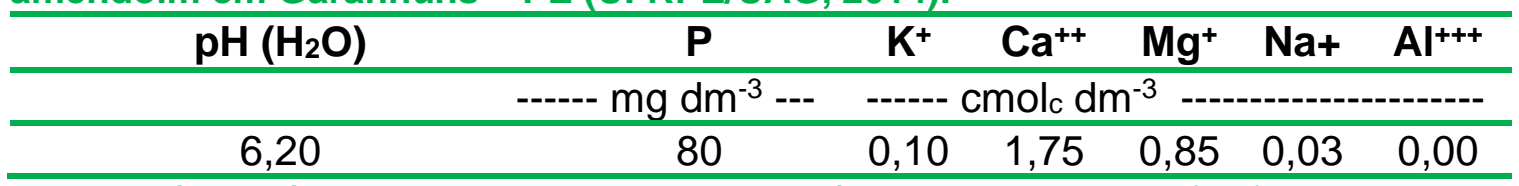

Fonte: Análise química realizada pelo Instituto Agronômico de Pernambuco (IPA).

Aplicou-se $5,9 \mathrm{~m}^{3} / \mathrm{ha}$ de resíduo lácteo 15 dias antes de realizar o semeio do amendoim, em sulcos na profundidade de $15 \mathrm{~cm}$, conforme determinado em testes anteriores ao experimento. De acordo com Gheri et al. (2003), este resíduo pode chegar a conter $1,3 \mathrm{~g} / \mathrm{L}$ de N, 1,1 g/L de $\mathrm{P}_{2} \mathrm{O}_{5}$ e 1,9 $\mathrm{g} / \mathrm{L}$ de $\mathrm{K}_{2} \mathrm{O}$. 
As sementes de amendoim foram inoculadas com estirpe de Bradyrhizobium comercial (Biomax ${ }^{\circledR}$ Premium Turfa - Amendoim) na dose de $120 \mathrm{~g} / 40 \mathrm{~kg}$ de sementes.

Foram realizadas avaliações de: emergência: foi feita a contagem do número de plântulas do quinto ao décimo dia após a semeadura, transformando em percentual e consideradas emergidas a partir de quando $o$ hipocótilo apareceu acima da superfície do solo, de acordo com Brasil (2009); Índice de velocidade de emergência: cálculo efetuado de acordo Melo (MAGUIRE, 1962 apud MELO, 2013), a contagem foi realizada diariamente do quinto dia até o décimo dia após o plantio; número de dias para emergência e número de folhas: contagem realizada diretamente nas plantas ao acaso; comprimento da parte aérea e da raiz: fez-se as medições de comprimento de parte aérea e raiz com o auxílio de régua graduada da superfície do solo até a extremidade da haste principal; massa seca de parte aérea e massa seca de raiz: após a medição dos comprimentos de parte aérea, as plantas foram divididas em parte aérea e raiz, colocadas em sacos de papel e levadas para estufa de circulação forçada de ar por 72 horas a $65^{\circ} \mathrm{C}$ e submetidas a pesagem.

Foi utilizado delineamento experimental de blocos ao acaso com parcelas subdivididas, com seis tratamentos com quatro repetições. Os resultados foram submetidos à análise de variância e as médias foram comparadas pelo teste de Tukey $(p<0,05)$. As análises estatísticas foram realizadas com auxílio do programa SISVAR, versão 5.3 (FERREIRA, 2010).

\section{Resultados e discussão}

Não houve diferença significativa em índice de velocidade de emergência e percentual de emergência do amendoim para os tratamentos avaliados (Tabela 2), diferente dos resultados de Nakagawa et al. (1994), que verificaram diminuição na porcentagem de emergência com aumento da densidade das plantas de amendoim utilizando a cultivar Tatu. A variável 
número de dias para emergência apresentou diminuição apenas no plantio de 3 linhas em consórcio com a palma forrageira.

Tabela 2. Índice de velocidade de emergência, taxa de emergência (\%) e número de dias para emergência de plantas de amendoim submetidas a diferentes populações de plantio em monocultivo e consorciado com palma gigante (UAG/ UFRPE, Garanhuns, 2014).

\begin{tabular}{ccc}
\hline \multirow{2}{*}{ Tratamentos } & \multicolumn{2}{c}{ Índice de velocidade de emergência } \\
\cline { 2 - 3 } 1 linhas & Monocultivo & Consórcio \\
\cline { 2 - 3 } 2 linhas & $12,06 \mathrm{aA}$ & $11,38 \mathrm{aA}$ \\
3 linhas & $12,53 \mathrm{aA}$ & $11,55 \mathrm{aA}$ \\
\hline \multirow{2}{*}{ Tratamentos } & $11,28 \mathrm{aA}$ & $11,90 \mathrm{aA}$ \\
\cline { 2 - 3 } & \multicolumn{2}{c}{ Emergência (\%) } \\
\hline 1 linhas & Monocultivo & Consórcio \\
2 linhas & $85,00 \mathrm{aA}$ & $84,80 \mathrm{aA}$ \\
3 linhas & $81,13 \mathrm{aA}$ & $81,25 \mathrm{aA}$ \\
Tratamentos & $81,41 \mathrm{aA}$ & $82,50 \mathrm{aA}$ \\
\hline 1 linhas & Número de dias para emergência \\
\hline 2 linhas & Monocultivo & Consórcio \\
3 linhas & $8,00 \mathrm{aA}$ & $8,25 \mathrm{aA}$ \\
& $7,75 \mathrm{aA}$ & $8,25 \mathrm{aA}$ \\
\hline
\end{tabular}

Médias seguidas de mesma letra minúscula na coluna e maiúscula na linha não diferem entre si pelo teste de Tukey ao nível de 5\%.

A Tabela 3 mostra os dados da área foliar de plantas de amendoim nos diferentes tratamentos, onde se observou menor área foliar apenas no tratamento de 3 linhas de plantio em consórcio, que pode ser ocasionada devido ao auto sombreamento no decorrer do desenvolvimento da cultura (PEIXOTO et al., 2009).

Tabela 3. Área foliar de plantas de amendoim submetidas a diferentes populações de plantio em monocultivo e em consórcio com palma forrageira. (UAG/ UFRPE, Garanhuns, 2014).

\begin{tabular}{ccc}
\hline Tratamentos & \multicolumn{2}{c}{ Área foliar $\left(\mathrm{cm}^{2}\right)$} \\
\hline & Monocultivo & Consórcio \\
\cline { 2 - 3 } 1 linhas & $17,72 \mathrm{aA}$ & $16,76 \mathrm{aA}$ \\
2 linhas & $17,23 \mathrm{aA}$ & $18,02 \mathrm{aA}$ \\
3 linhas & $18,93 \mathrm{aA}$ & $13,76 \mathrm{aB}$ \\
\hline
\end{tabular}

Médias seguidas de mesma letra minúscula na coluna e maiúscula na linha não diferem entre si pelo teste de Tukey ao nível de 5\%. 
De acordo com a Tabela 4, não houve diferença significativa para massa seca da parte aérea e da raiz das plantas de amendoim nos tratamentos avaliados. Andrade (2012) fez um trabalho semelhante, e concluiu que este resultado pode colaborar para a indicação de plantio em maior população, podendo promover aumento da biomassa.

Sobre avaliações da massa seca da parte aérea e radicular, Ramos et al. (2004) relata que estas são variáveis de grande importância na avaliação do desenvolvimento das plantas, assegurando o estabelecimento destas no campo.

Tabela 4. Massa seca e comprimento de parte aérea e raiz de plantas de amendoim submetidas a diferentes populações de plantio em sistema solteiro e consorciado com palma forrageira. (UAG/ UFRPE, Garanhuns, 2014).

\begin{tabular}{|c|c|c|}
\hline \multirow[t]{2}{*}{ Tratamentos } & \multicolumn{2}{|c|}{ Massa seca da parte aérea (g) } \\
\hline & Monocultivo & Consórcio \\
\hline 1 linhas & 7,76 aA & $6,13 \mathrm{aA}$ \\
\hline 2 linhas & 6,86 aA & $6,31 \mathrm{aA}$ \\
\hline 3 linhas & $6,43 \mathrm{aA}$ & $4,74 \mathrm{aA}$ \\
\hline \multirow[t]{2}{*}{ Tratamentos } & \multicolumn{2}{|c|}{ Massa seca da raiz (g) } \\
\hline & Monocultivo & Consórcio \\
\hline 1 linha & 0,66 aA & $0,64 \mathrm{aA}$ \\
\hline 2 linhas & $0,69 \mathrm{aA}$ & $0,74 \mathrm{aA}$ \\
\hline 3 linhas & $0,64 \mathrm{aA}$ & 0,66 aA \\
\hline \multirow[t]{2}{*}{ Tratamentos } & \multicolumn{2}{|c|}{ Comprimento da raiz $(\mathrm{cm})$} \\
\hline & Monocultivo & Consórcio \\
\hline 1 linha & $12,95 \mathrm{aA}$ & $13,09 \mathrm{aA}$ \\
\hline 2 linhas & 11,39 aA & $12,98 \mathrm{aA}$ \\
\hline 3 linhas & $13,23 \mathrm{aA}$ & $11,99 \mathrm{aA}$ \\
\hline \multirow[t]{2}{*}{ Tratamentos } & \multicolumn{2}{|c|}{ Comprimento da parte aérea $(\mathrm{cm})$} \\
\hline & Monocultivo & Consórcio \\
\hline 1 linha & $10,05 \mathrm{aB}$ & 16,76 aA \\
\hline 2 linhas & $9,27 \mathrm{aB}$ & $18,02 \mathrm{aA}$ \\
\hline 3 linhas & $10,71 \mathrm{aB}$ & $13,76 \mathrm{bA}$ \\
\hline
\end{tabular}

Médias seguidas de mesma letra minúscula na coluna e maiúscula na linha não diferem entre si pelo teste de Tukey ao nível de 5\%.

Ainda de acordo com a Tabela 4, os dados de comprimento da parte aérea expressaram diferenças significativas, onde na maior densidade de plantio em consórcio ocorreu a diminuição do comprimento da parte aérea das plantas de amendoim e aumento do comprimento nas linhas de amendoim em 
consórcio em relação ao monocultivo de amendoim, mas os tratamentos não apresentaram diferença significativa no comprimento da raiz. Isto pode ser resultado de um solo com baixa porosidade na sua estrutura.

Em trabalhos realizados por Bellettini et al. (2001), Gonçalves (2004) e Peixoto et al. (2008) foram observados resultados diferentes em amendoim, com diminuição na altura das plantas ao passo que aumentavam a densidade.

\section{Conclusões}

O consórcio de amendoim com palma forrageira incrementou 0 desenvolvimento do amendoim, sendo o melhor tratamento observado o plantio de duas linhas de amendoim em consórcio com palma. 


\section{Referências}

ALTIEIRI, M.A., SILVA, E.N., NICHOLLS, C.I. O papel da biodiversidade no manejo de pragas. Ribeirão Preto: Holos, 2003. 226 p.

ANDRADE, J. A. S.; Produção de amendoim consorciado com palma forrageira no agreste meridional Pernambucano. 2012. 68 f. Dissertação (Mestrado) - Programa De Pós-Graduação Em Produção Agrícola, Universidade Federal Rural de Pernambuco - Unidade Acadêmica de Garanhuns, Garanhuns, 2012.

BELLETTINI, N. M. T.; ENDO, R. M. Comportamento do amendoim "das águas", Arachis hypogaea L., sob diferentes espaçamentos e densidades de semeadura. Acta Scientiarum: Agronomy. Maringá, v. 23, n. 5, p. 1249-1256, 2001.

BEZERRA NETO, F.; TORRES FILHO, J.; HOLANDA, J.S.; SANTOS, E.F.; ROSADO, C. A. S. Efeito do sistema de cultivo e arranjo espacial no consórcio algodão herbáceo + caupi + sorgo. Pesquisa Agropecuária Brasileira, Brasília, v. 26, n.5, p. 715-727, 1991.

BRASIL. MINISTÉRIO DA AGRICULTURA, PECUÁRIA E ABASTECIMENTO. SECRETARIA DE DEFESA AGROPECUÁRIA. Regras para análise de sementes. 2009. 399 p.

CAVALCANTI, FJ de A. Recomendações de adubação para o Estado de Pernambuco: $2^{\mathrm{a}}$ aproximação. Ed. IPA, Recife, PE, 2008.

FERREIRA, D. F. Sisvar: a computer statistical analysis system. Ciência e Agrotecnologia (UFLA), v. 35, n.6, p. 1039-1042, 2010.

FERREIRA, M. A,; SILVA, F. M.; BISPO, S. V. AZEVEDO, M. Estratégias na suplementação de vacas leiteiras no semiárido do Brasil. Revista Brasileira de Zootecnia. Lavras. v. 38, p.322-329, 2009 (suplemento especial).

GHERI, E. O.; FERREIRA, M. E.; CRUZ, M. C. P.; Resposta do capim-tanzânia à aplicação de soro ácido de leite. Pesquisa Agropecuária Brasileira, v.38, n.6, p.753-760, 2003.

GONÇALVES, J. A.; Arranjo espacial no crescimento e rendimento de amendoim em duas épocas de semeadura no Recôncavo Baiano. 2004. 97f. Dissertação (Mestrado) - Curso De Pós-Graduação Em Ciências Agrárias, Centro de Ciências Agrárias e Ambientais, Universidade Federal da Bahia, Cruz das Almas, 2004.

KASAI, F. S.; DEUBER, R. Manejo de plantas daninhas na cultura do amendoim. Campinas: Instituto Agronômico, 2011. 23p. (Série Tecnologia APTA. Boletim Técnico IAC, 207). 
LIMA, T. M. de. Cultivo do amendoim submetido a diferentes níveis de adubação e condições edafoclimáticas no sudoeste de Goiás. 2011. 133 f. Dissertação (Mestrado) - Programa De Pós-Graduação Em Agronomia, Universidade Federal de Goiás - Campus Jataí, 2011.

MELO, J. P. R. de. Técnicas de cultivo para produção de biomassa e grãos de soja. 2013. 78 f. Dissertação (Mestrado em Produção Agrícola) Universidade Federal Rural de Pernambuco - Unidade Acadêmica de Garanhuns, 2013.

MILKPOINT. MG: Resíduo de laticínio pode ser usado como adubo. 2009. Disponível em: http://www.milkpoint.com.br/cadeia-do-leite/giro-lacteo/mgresiduo-de-laticinio-pode-ser-usado-como-adubo-56922n.aspx. Acesso em: 22 jul. 2020.

NAKAGAWA, J.; LASCA, D. C.; NEVES, J. P. S.; NEVES, G. S. N. SANCHES, S. V.; BARBOSA, V.; SILVA, M. N.; ROSSETTO, C. A. V. Efeito da densidade de semeadura na produção do amendoim. Pesquisa Agropecuária Brasileira. Brasília, v.29.n.10. p.1547-1555, 1994.

PEIXOTO, C. P.; GONÇALVES, J. A.; PEIXOTO, M. F. S. P.; CARMO, D. O. Características agronômicas e produtividade de amendoim em diferentes espaçamentos e épocas semeadura no Recôncavo Baiano. Bragantia, Campinas, v.67, n.3, p.563-568, 2008.

PEIXOTO, M. J. A. Crescimento Vegetativo, Produção e Composição Químico-Bromatológica da Palma Forrageira Consorciada com Cajá Spondias spp. 2009. 78 f. Dissertação (Mestrado em Zootecnia) Universidade Federal do Ceará, 2009.

RAMOS, K. M. O.; FELFILI, J. M.; FAGGI, C. W.; SOUZA-SILVA, J. C.; FRANCO, A. C. Crescimento inicial e repartição da biomassa de Amburana cearensis (Allemao) A. C. Smith. Em diferentes condições de sombreamento. Acta Botânica Brasílica, São Paulo, v.18, n.2, 2004. p. 351-358.

SANTOS, D.C.; FARIAS, I.; LIRA, M.A. et al. Manejo e utilização da palma forrageira (Opuntia e Nopalea) em Pernambuco. Recife: Instituto Agronômico de Pernambuco, 2006. 48p. (Documentos, 30). 